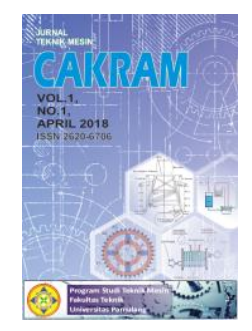

\title{
KAJIAN POTENSI ANGIN SEBAGAI ENERGI ALTERNATIF DAN TERBARUKAN PEMBANGKIT LISTRIK DI UNIVERSITAS PAMULANG
}

\author{
Ihat Solihat ${ }^{1}$,Fifit Astuti ${ }^{2}$, Agustina Dyah Setiyowati ${ }^{3}$ \\ ${ }^{\text {I} P r o g r a m ~ S t u d i ~ T e k n i k ~ M e s i n, ~ U n i v e r s i t a s ~ P a m u l a n g, ~ J l . ~ S u r y a ~ K e n c a n a ~ N o . ~ 1, ~ T a n g e r a n g ~ S e l a t a n, ~ I n d o n e s i a ~}$ \\ Email : dosen00990@unpam.ac.id
}

Masuk : 28 Juli 2018

Direvisi : 21 September2018 Disetujui :2 Oktober 2018

\begin{abstract}
Abstrak: Energi merupakan kebutuhan vital manusia sepanjang zaman. Energi dapat didefinisikan sebagai kemampuan yang diperlukan untuk melakukan usaha. Angin sebagai Sumber daya alam yang begitu melimpah menjadi sebuah energi alternatif yang belum banyak di manfaatkan.Pengukuran kecepatan angin di gedung A universitas Pamulang pada ketinggian $5 \mathrm{~m}$ di waktu pagi dan siang hari di 5 titik pengambilan yang diperoleh data pada titik 3 di pagi hari dan titik 4 di siang hari dengan kecepatan $1,7 \mathrm{~m} / \mathrm{s}$ dan $3,7 \mathrm{~m} / \mathrm{s}$ dengan daya yang dihasilkan yaitu 350 Watt. Hasil pengukuran kecepatan tersebut diguanakan sebagai acuan dalam pembuatan prototype PLTA. Prototype menggunakan pipa paralon dan vleg roda sepeda yang dirancang dengan diameter roda $50 \mathrm{~cm}$ dan panjang pipa $100 \mathrm{~cm}$. Prototype ini berhasil di ujicoba dengan pemutarannya menggunakan kipas angin dengan inidkator LED yang menyala.
\end{abstract}

Kata kunci: angin, kecepatan, prototype PLTA

Abstract: Energy is a vital human need throughout the ages. Energy can be defined as the ability required to do business. Wind as an abundant natural resource becomes an alternative energy that has not been widely utilized. Measurement of wind speed in building A university Pamulang at a height of $5 \mathrm{~m}$ in the morning and afternoon at 5 point retrieval obtained data at point 3 in the morning and Point 4 in the daytime with a speed of $1.7 \mathrm{~m} / \mathrm{s}$ and $3.7 \mathrm{~m} / \mathrm{s}$ with the power produced is 350 watts. Speed measurement results are apply as a reference in the manufacture of prototype hydropower. Prototype uses pipes and vleg bike wheels designed with a $50 \mathrm{~cm}$ diameter wheel and $100 \mathrm{~cm}$ pipe length. This prototype successfully tested with playback using a fan with LED inidkator that lights up.

Keywords : Energy, Speed Wind, Prototype Hydropower

\section{PENDAHULUAN}

Energi merupakan kebutuhan vital manusia sepanjang zaman. Energi dapat didefinisikan sebagai kemampuan yang diperlukan untuk melakukan usaha. Sumber energi yang banyak digunakan manusia berasal dari alam. Sumber Energi yang banyak dimanfaatkan selama ini didepoleh dari bahan bakar fosil yaitu solar, bensin, minyak bumi, batu bara, bensin dan gas alam. Bahan bakar fosil berasal dan tumbhan dan jasad hewan purba. Kelemahan dari bahan bakar fosil adalah dapat menimbulkan polusi. Bahan bakar fosil tidak dapat diperbarui karena proses pembentukannya sendiri memakan waklu berjuta-juta tahun lamanya. Penggunaan yang terus menerus akan menyebabkan bahan bakar fosil ini semakin habis sehingga perlu dikembangkan sumber energi alternatif yang berasal dari sumner daya alam yang

dapat diperbarahui seperti energi matahari, air dan angin, energi panas bumi dan energi pasang air laut. [2]

Krisis energi di Indonesia sudah pada ambang batasnya dimana menurut data yang dihimpun kompas pada tanggal 21 Maret 2015 lalu bahwa cadangan minyak Indonesia di perkirakan akan habis 11 tahun mendatang. Oleh karena itu jika Indonesia hanya bergantung pada sumber energi fosil maka akan habis, padahal potensi Indonesia sebagai negara tropis memiliki begitu banyak energi alternatif yang apabila dikelola dengan tepat akan menghasilkan energi yang besar sebagai pengganti energi fosil. Indonesia masih memiliki 29.000 megawatt potensi panas bumi dan baru dimanfaatkan sekitar 5 persen. Penggunaan gas juga harus dioptimalkan 
karena Indonesia punya cadangan cukup besar, yaitu 103 triliun kaki kubik. Pengembangan energi baru terbarukan harus konsisten meskipun harga minyak dunia lemah. [2]

Teknologi tenaga angin, sumber energi paling cepat berkembang di dunia, sepintas terlihat sederhana. Namun dibalik menara tinggi, langsung dan bilahan besi putar terdapat pergerakan yang kompleks dari bahanbahan yang ringan seperti desain aerodinamis dan komputer yang dijalankan secara elektronik. Tenaga ditransfer melalui baling-baling, kadang dioperasikan pada variable kecepatan, lalu ke generator (meskipun beberapa turbin menghindari kotak peralatan dengan menjalankan langsung).[3]

Selama beberapa tahun terakhir pemasangan kapasitas angin meningkat melebihi $30 \%$. Hal tersebut membuat target untuk menjadikan tenaga angin mampu memenuhi kebutuhan energi dunia hingga 12 persen pada tahun 2020 menjadi realistis. Di saat bersamaan hal tersebut juga akan membuka kesempatan terbukanya lapangan pekerjaan hingga dua juta dan mengurangi emisi CO2 hingga 10.700 juta ton.[2]

Besarnya potensi tenaga angin sebagai tenga alternatif yang dapat dipebarahui menjadikan latar belakang membuat generator angin yang dapat dimanfaatkan sebagai sumber energi khususnya bagi kawasan kampus Universitas Pamulang. Penelitian ini dibatasi pada pengukuran kecepatan angin hanya di lantai 5 dan 6 gedung A Universitas Pamulang. Perumusan masalah terdiri dari bagaimana potensi tenaga angin yang berada di wilayah kampus Universitas pamulang khususnya di lantai 5 dan 6, dan bagaimana memanfaatkan potensi tenaga angin yang berada wilayah kampus Universitas pamulang gedung A lantai 5 dan 6 . Berdasarkan uraian tersebut makan penelitian ini bertujuan untuk mengukur besarnya kecepatan Angin di kampus I Unpam gedung A lantai 5 dan 6 sekaligus Membuat prototipe generator pembangkit listrik tenaga angin yang mampu diaplikasikan di Kampus I universitas Pamulang.

\section{METODOLOGI}

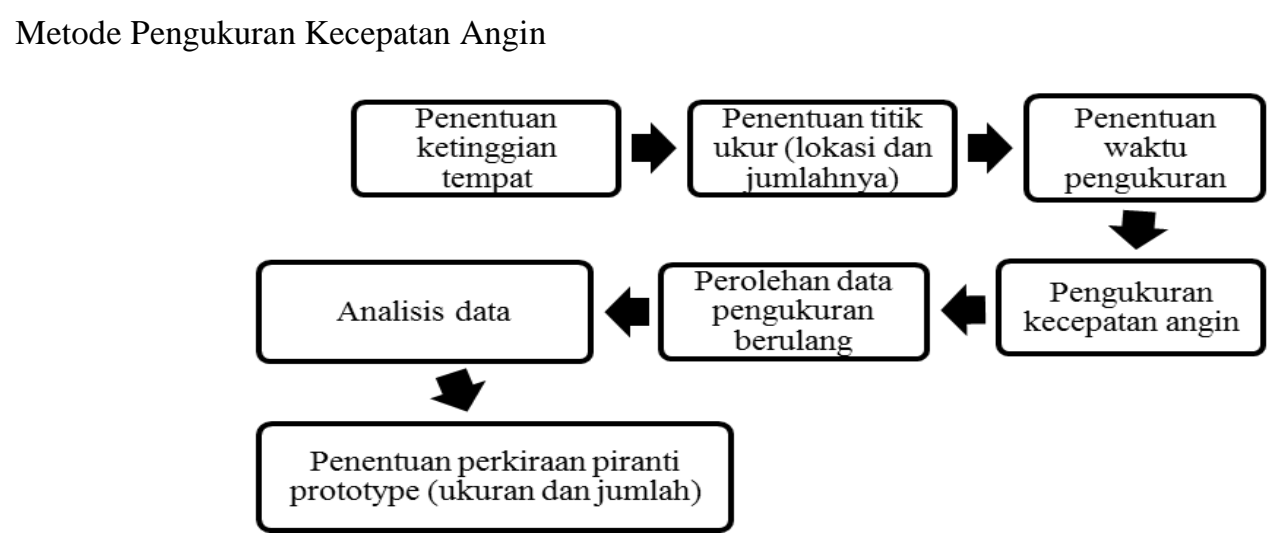

Gambar 1. Alur Pembuatan Prototype

Penelitain ini juga melakukan pengukuran kecepatan angin, berikut skema pengukuran kecepatan angin di gedung Pusat kampus UNPAM lantai 5:

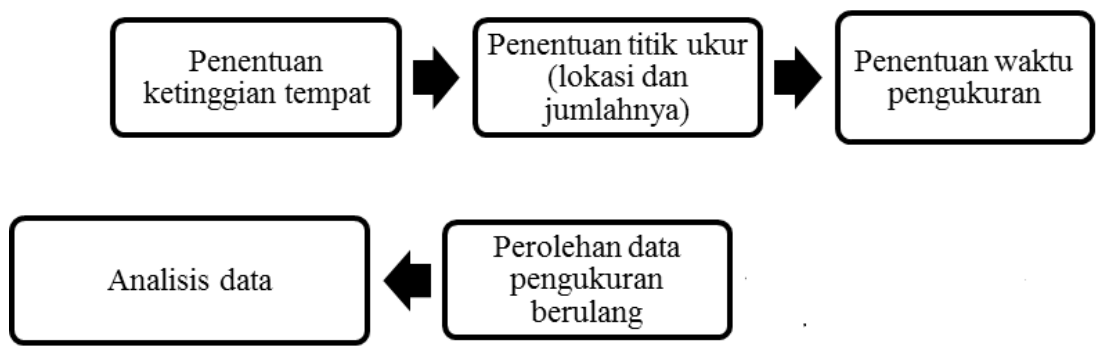

Gambar 2. Alur Pengambilan Data Kecepatan Angin 
Setelah diperoleh data pengukuran maka dibuatlah prototype generator angina sebagai berikut :

1. Generator mini yang sudadibeli di test dengan cara menyambungkan dengan LED.

2. Pipa seanjang $100 \mathrm{~m}$ dipotong menjadi dua bagian.

3. Besi sebaga kerangka dilas agar menjadi bentuk yang diinginkan

4. Pengecetan kerangka besi dengan warna hitam dan vleg roda dengan warna biru.

5. Pemasangan vleg pada kerangka atas dan bawah dilanjutkan dengan pemasangan pipa paralon sebagai baling-baling PLTA.

6. Pemasangan generator mini dan LED di atas rangka yang sudah tersusun.

7. PLTA digerakan dengan kipas angin untuk menyalakan lampu LED.

\section{HASIL DAN PEMBAHASAN}

\section{Pengaruh Tempat Terhadap Kecepatan Angin dan Luas Penampang}

Untuk mengetahui potensi angin dikaitkan dengan berapa besar daya yang akan dihasilkan dari kecepatan angin, kami melakukan pengukuran kecepatan angin pada waktu pagi hari dan siang hari serta pada titik yang berbeda. Pengukuran yang dilakukan sebanyak 5 (lima) kali di setiap titik di lima lokasi pada waktu pagi dan siang.

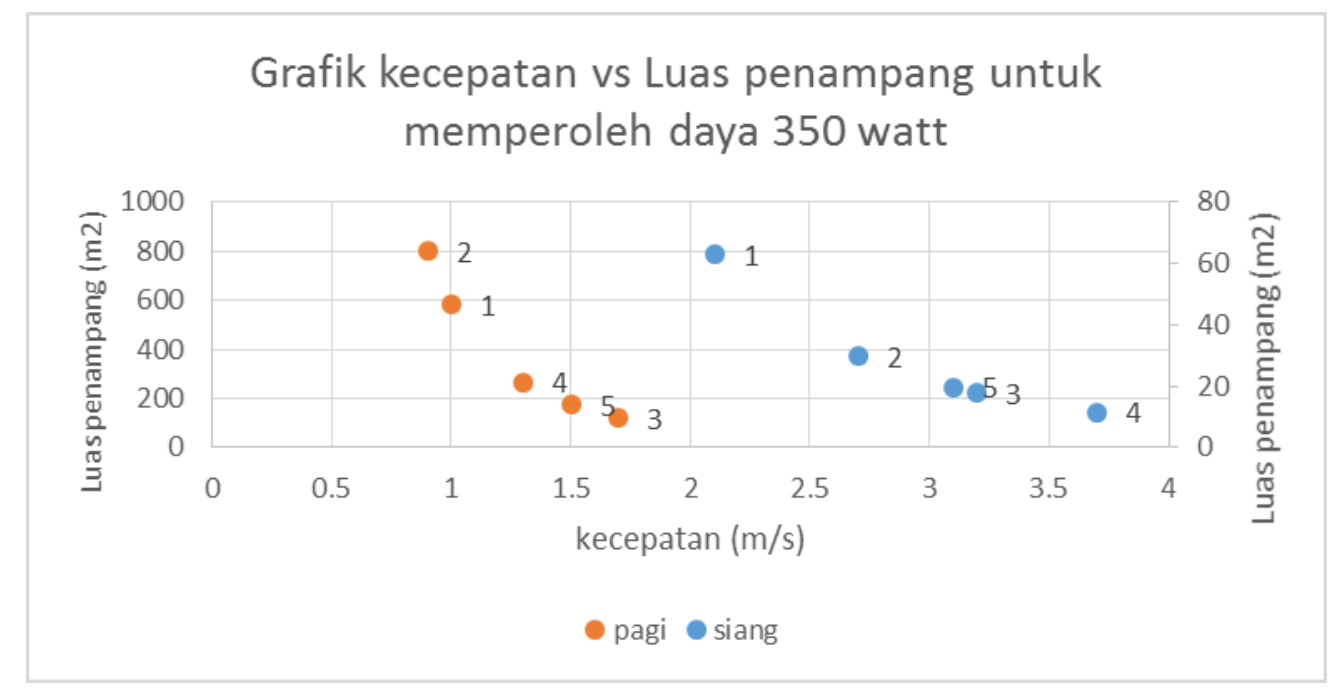

Gambar 4.1 garfik hubungan kecepatan dengan luas penampang

Data yang diperoleh pada waktu yang berbeda dan pada tempat yang berbeda dengan kode 1, 2, 3, 4 dan 5 dapat dilihat pada tempat 3 (pagi) dan 4 (siang) yang memiliki kecepatan angin paling besar yaitu secara berturut turut $1,7 \mathrm{~m} / \mathrm{s}$ dan $3,7 \mathrm{~m} / \mathrm{s}$. Dapat dilihat pula pada grafik yaitu hubungan berbanding terbalik antara kecepatan angin dan luas penampang, pada kecepatan angin paling besar didapatkan luas penampang terkecil. Luas penampang hasil perhitungan dan analisis inilah yang nantinya diharapkan menjadi dasar pembuatan prototype pembangkit listrik tenaga angin di lingkungan Unpam. Berikut table 1 mengenai pengukuran kecepatan angin per waktu pagi dan siang.

Tabel 1. Hasil Pengukuran Kecepatan Angin dan Perhitungan Luas Penampang Kipas

\begin{tabular}{|l|l|l|l|}
\hline \multicolumn{2}{|l|}{ PAGI } & \multicolumn{2}{|l|}{ SIANG } \\
\hline $\begin{array}{l}\text { KECEPATAN } \\
(\mathrm{m} / \mathrm{s})\end{array}$ & $\begin{array}{l}\text { LUAS } \\
(\mathrm{m} 2)\end{array}$ & $\begin{array}{l}\text { KECEPATAN } \\
(\mathrm{m} / \mathrm{s})\end{array}$ & $\begin{array}{l}\text { LUAS } \\
(\mathrm{m} 2)\end{array}$ \\
\hline 1 & 583.3333 & 2.1 & 62.98816 \\
\hline 0.9 & 800.1829 & 2.7 & 29.6364 \\
\hline 1.7 & 118.7326 & 3.2 & 17.80192 \\
\hline 1.3 & 265.5136 & 3.7 & 11.51626 \\
\hline 1.5 & 172.8395 & 3.1 & 19.58086 \\
\hline
\end{tabular}




\section{Pembuatan Prototype Pembangkit Listrik Tenaga Angin}

Untuk pembuatan prototype mengacu pada hasil perhitungan luas penampang yang didapatkan dari tabel 1, diambil kecepatan angin terbesar yaitu pada titik ke 3 (pagi) dan 4 (siang)

Pagi :

Luas penampang : $118,73 \mathrm{~m} 2$

$A=\pi r^{2}$

$118,73=\pi r^{2}$

$r=\sqrt{\frac{118,73}{\pi}}=6,15 m$

Siang.

Luas penampang : $11,52 \mathrm{~m} 2$

$A=\pi r^{2}$

$$
11,52=\pi r^{2}
$$

$r=\sqrt{\frac{11,52}{\pi}}=1,92 \mathrm{~m}$

Luas penampang yang didapatkan harapannya menjadi dasar pembuatan prototype pembangkit listrik tenaga angin, dari luas penampang yang dianalogikan sebagai putaran baling-baling kipas yaitu berbentuk lingkaran maka didapatkan jari-jari baling-baling kipas sebesar kurang lebihnya 6,15 m dan 1, $92 \mathrm{~m}$.

Untuk prototype pembangkit listrik tenaga angin yang akan kita buat menggunakan ukuran jari-jari 0,96 m, setengah ukuran sebenarnya hal ini karena jari jari terlalau besa. Baling baling yang dibuat menggunakan baling baling dari paralon panjangsekitar $100 \mathrm{~cm}$ yang dibagi dua. Pembangkit ini di uji dengan menyalakan LED sebagai indikator adanya tenaga listrik yang terjadi. Harpannya pembuatan protype ini bisa menjadi pertimbangan untuk pembangkit listrik alternatif (menyalakan AC ) pada siang hari di Universitas Pamulang gedung A karena udara siang hari yang lebih panas. Berikut desaian prototype sebelum dibuat

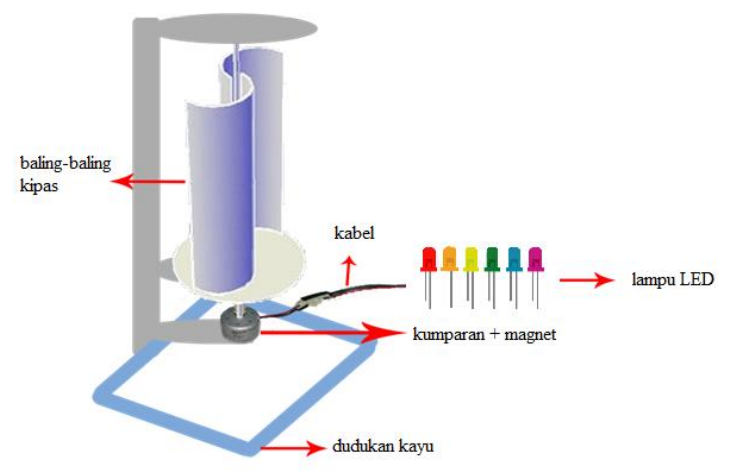

Gambar 3. Desain prototype pembangkit listrik tenaga angin skala kecil

Hasil Pembuatan prototype PLTA seperti berikut:

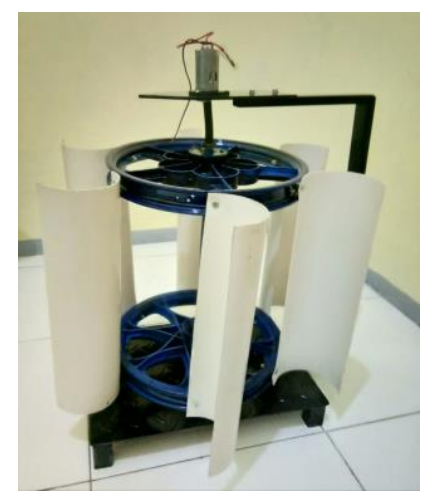

Gambar 4. kerangka awal pembuatan prototype 
Simulasi pada kipas untuk bisa menyalakan lampu LED.

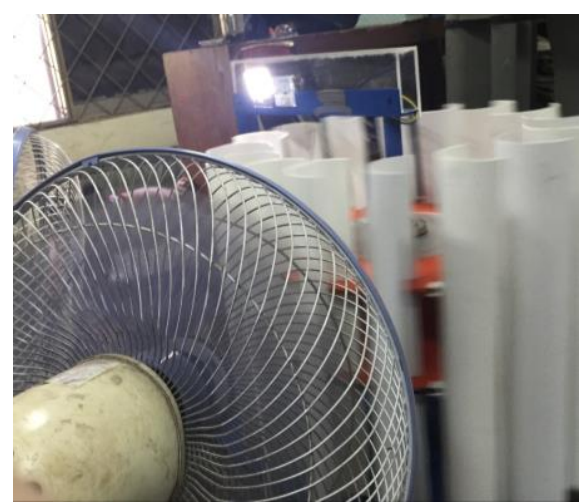

Gambar 5. Pengecekan PLTA dengan kipas angin untuk menyalakan lampu LED

Dari hasil pembuatan prototype dan hasil pengukuran kecepatan angin yang ada di daerah universitas Pamulang gedung A dijadikan energi alrenaif setidaknya untuk lampu pada malam hari dan AC untuk siang hari. Dibutuhkan instalasi PLTA dengan diameter yang cukup besar agar menghasilkan energi listrik yang bisa digunakan di gedung A Universitas Pamulang.

\section{KESIMPULAN DAN SARAN}

Dari hasil penelitian, maka dapat disimpulkan :

1. Hasil pengukuran kecepatan angin di kampus Universitas Pamulang gedung A diambil dengan 2 waktu yaitu, pagi dan siang. Kecepatan terbesar pada titik 3 untuk pagi hari dan titik ke 4 siang hari yaitu $1,7 \mathrm{~m} / \mathrm{s}$ dan $3,7 \mathrm{~m} / \mathrm{s}$. Dari kecepatan yang diukur dapat diketahui daya listrik yang dihasilkan dan juga sebagai dasar pembuatan prototype yang akan dibuat.

2. Prototype PLTA berhasil dibuat dengan indikator nyala lampu pada LED yang dipasang dengan bantuan kipas angin.

Adapun saran yang dapat diberikan adalah :

1. Perlu adanya langkah serius dalam pembuatan energi alternatif di kampus UNPAM pusat gedung A yang memanfaatkan angin sebagai energi alternatif.

2. adanya uji joba PLTA yang dibuat lebih besar di wilayah kampus UNPAM pusat gedung A.

\section{DAFTAR PUSTAKA}

[1] 2007. UU No 30 Tahun 2007 tentang Energi. Bab I Pasal I : ayat 5. Pemerintah Republik Indonesia : Jakarta

[2] Elias K. Bawan .Analisa Potensi Energi Terbarukan Di Kabupaten Kaimana Propinsi Papua Barat .2017. jurnal smartek

[3] Ikhwan,I. dan M.A. Hipi. 2011. Analisis Pengaruh Pembebanan Terhadap Kinerja Kincir Angin Tipe Propeller Pada Wind Tunnel Sederhana. http://repository.unhas.ac.id/bitstream/ diakses 24 Oktober 2017 